\title{
Left atrial myxoma in association with life-saving mitral stenosis
}

\author{
Philippe Demers, MD, FRCSC, ${ }^{\mathrm{a}, \mathrm{b}}$ and Nicolas Beaulieu, MD, ${ }^{\mathrm{b}}$ Montreal, Quebec, Canada
}

Video clip is available online.

This case report highlights the occurrence of a free left atrial myxoma with concomitant mitral stenosis (Videos 1 and 2). Myxomas, although rare, are the most common benign cardiac tumors. They are generally located in the left atria $(75 \%)$, most often attached by a stalk to the endocardium and growing toward 1 or more of the heart's cavities. Their average size is $5 \mathrm{~cm}$ in diameter. Although most are pedunculated, attached by a broad base, and relatively immobile, a small portion are attached by a long stalk or even unattached, leading to many possible complications, which are separated into (1) obstructive complications, (2) embolization, and (3) constitutional symptoms. ${ }^{1,2}$ The dislodgement of the mass near on orifice is a cause for obstruction. When this occurs near the mitral valve, it leads to a mitral stenosis. The mass can also embolize, most commonly manifesting as central nervous system disturbances.

Because of the amelioration of the management of rheumatic fever, mitral stenosis is of decreasing incidence; however, it is still more common than myxoma in the general population. Mitral stenosis usually presents with significant dyspnea and can be associated with atrial fibrillation and thrombus formation. The association of myxoma and mitral stenosis is extremely rare, with only a handful of cases being reported in the literature. ${ }^{3}$

\section{CLINICAL SUMMARY}

A 70-year-old woman was initially admitted for hematochezia with epigastric burning pain radiating to the umbilical region. The patient also presented with a short episode of atrial fibrillation. For the past 2 years, she experienced progressive dyspnea, which was graded II-III/IV with

\footnotetext{
From the Department of Surgery, ${ }^{\text {a }}$ Montreal Heart Institute and Université de Montréal; and the Faculty of Medicine, ${ }^{\mathrm{b}}$ Université de Montréal, Montreal, Quebec, Canada.

Disclosures: Authors have nothing to disclose with regard to commercial support.

Received for publication Sept 12, 2011; revisions received Oct 5, 2011; accepted for publication Oct 26, 2011

Address for reprints: Philippe Demers, MD, FRCSC, Department of Surgery,

Montreal Heart Institute, 5000 Belanger St, Montreal, Quebec H1T 1C8, Canada

(E-mail: chagnondemers@ videotron.ca).

J Thorac Cardiovasc Surg 2012;143:e9-10

$0022-5223 / \$ 36.00$

Copyright $(2012$ Published by Elsevier Inc. on behalf of The American Association

for Thoracic Surgery

doi:10.1016/j.jtcvs.2011.10.084
}
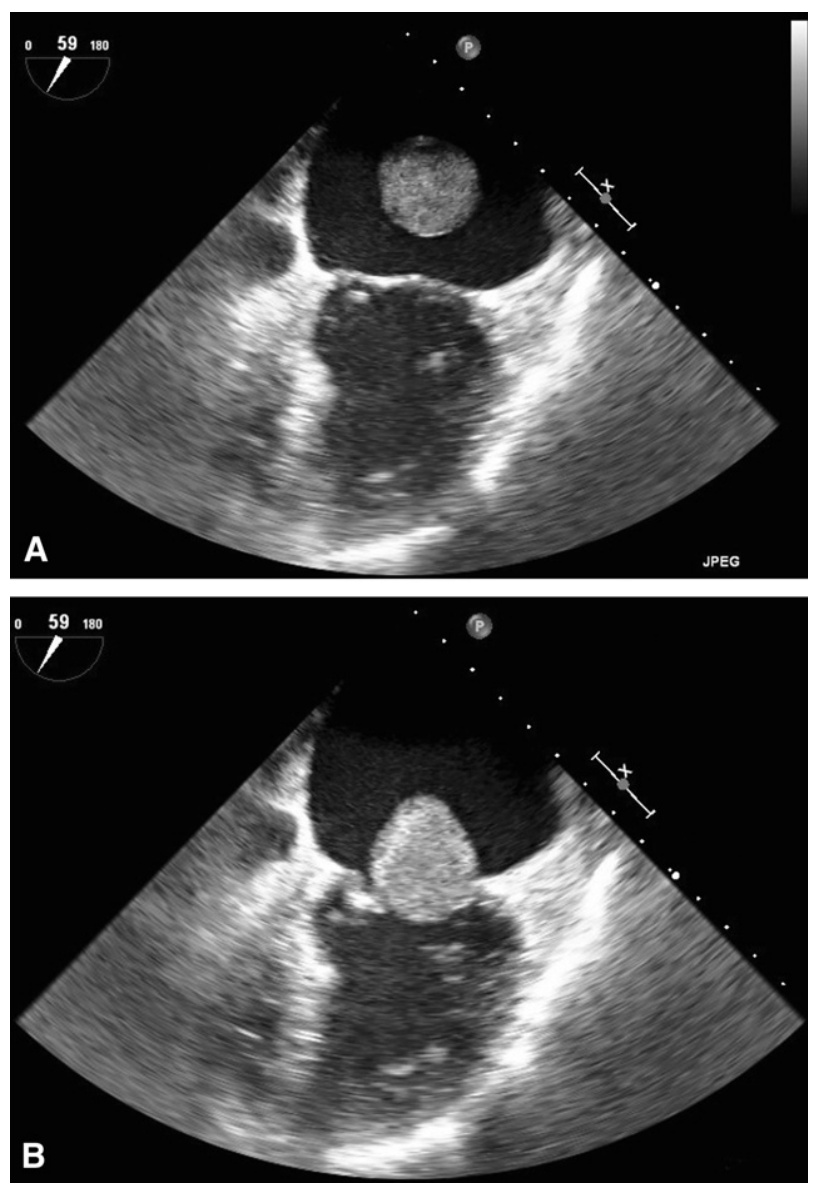

FIGURE 1. Intraoperative transesophageal echocardiogram showing the free-floating myxoma in the left atrium (A) and the myxoma obstructing the mitral valve orifice at end-diastole (B).

nonproductive cough. A concomitant thrombocytopenia of unknown cause was present, for which the patient was transfused with platelets and given intravenous immunoglobulin G. After performing a transesophageal echocardiogram for the atrial fibrillation, a large 4-cm myxoma was found in the left atria. The left ventricular dimensions were normal; left ventricular ejection fraction was $60 \%$. An urgent coronarography was performed.

Surgical intervention was scheduled to remove the myxoma. Through the use of intraoperative transesophageal echocardiography, the patient was found to have a free-floating myxoma in addition to a mitral stenosis, which was preventing embolization of the myxoma (Figure 1).

A median sternotomy was performed, and cardiopulmonary bypass was initiated with aortobicaval cannulation. 
The operation was divided into (1) removal of the free myxoma in the left atria, (2) resection of the site of the remnant myxoma pedicle located near the fossa ovalis, and (3) mitral valve replacement with a mechanical prosthesis (no. 27 St Jude; St Jude Medical, Inc, St Paul, Minn). Commissurotomy was not performed because of the presence of heavily calcified commissures. Weaning from cardiopulmonary bypass was easily performed, and the patient was extubated on the same day and discharged on day 8. Apart from pleural effusion and short-lasting atrial fibrillation, no early complications occurred. The patient was seen a month after the operation and has recovered well. The gastrointestinal bleeding for which the patient consulted is thought to have been explained by an ischemic colitis caused by microemboli from the resection of a polyp before the operation or from the myxoma. As for the thrombocytopenia, immune thrombocytopenic purpura might be the explanation.

\section{DISCUSSION}

The combination of left atrial myxoma and mitral stenosis is extremely rare. With mitral stenosis often predisposing to thrombus formation, the myxoma could have easily been mistaken as such; hence the transesophageal echocardiogram proved to be very useful in making this distinction. ${ }^{4}$ Although the complications are similar, the management of a myxoma is essentially surgical. In addition, the initial presentation of this patient, hematochezia with abdominal pain, is not usually how a myxoma presents. The association of a right atrial myxoma with extensive colonic polyposis ${ }^{5}$ has been reported once in the medical literature, making one question a possible link between the 2 conditions (with a left atrial myxoma in this case). In conclusion, in this patient's case the rare association of left atrial myxoma and mitral stenosis was proved to be life saving by preventing a potentially tragic embolic complication, such as a cerebrovascular accident.

\section{References}

1. Walkes J-CM, Smythe WR, Reardon MJ. Cardiac neoplasms. In: Cardiac surgery in the adult. 3rd ed. New York: McGraw-Hill; 2008. p. 1479-510.

2. Pinede L, Duhaut P, Loire R. Clinical presentation of left atrial cardiac myxoma. A series of 112 consecutive cases. Medicine (Baltimore). 2001;80:159-72.

3. Matana A, Zaputovic L, Simic O, Kastelan ZM. The protective effect of mitral stenosis on the embolization of a free-floating left atrial myxoma. Eur J Echocardiogr. 2006;7:322-5.

4. Khania M, Hekmat M. A patient with rheumatic mitral stenosis and an atrial myxoma. Eur J Echocardiogr. 2003;4:229-31.

5. Janosi A, Moravcsik E, Faller J, Adam Z, Bodo M. [Simultaneous occurrence and treatment of right atrial myxoma and extensive colonic polyposis causing recurrent intestinal hemorrhages]. Orv Hetil. 1996;137:1647-50.

\title{
Cardiac herniation during robot-assisted cardiac operation
}

\author{
Shojiro Yamaguchi, MD, PhD, Norihiko Ishikawa, MD, PhD, and Go Watanabe, MD, PhD, Kanazawa, \\ Japan
}

Video clip is available online.

Cardiac herniation during a cardiac operation is extremely rare. We report a rare case of intraoperative cardiac

\footnotetext{
From the Department of General and Cardiothoracic Surgery, Kanazawa University, Kanazawa, Japan.

Disclosures: Authors have nothing to disclose with regard to commercial support.

Received for publication Sept 14, 2011; revisions received Oct 13, 2011; accepted for publication Oct 26, 2011

Address for reprints: Shojiro Yamaguchi, MD, PhD, Department of General and Cardiothoracic Surgery, Kanazawa University, Takaramachi 13-1, Kanazawa 920-8641, Japan (E-mail: gucci-s@ya2.so-net.ne.jp).

J Thorac Cardiovasc Surg 2012;143:e10-11

0022-5223/ $\$ 36.00$

Copyright (c) 2012 by The American Association for Thoracic Surgery

doi:10.1016/j.jtcvs.2011.10.077
}

herniation. Our patient had herniation develop in response to strong positive ventilation to the left lung.

\section{CLINICAL SUMMARY}

A 20-year-old male patient was referred to our institution to undergo robot-assisted atrial septal defect (ASD) closure. The patient had typical primum type ASD, and a part of the rim was thin, so closure with a catheter was not recommended. We decided to perform robot-assisted minimally invasive procedure for ASD patch closure. With the patient under general anesthesia, the operation was started with left-sided single-lung ventilation, a right radial arterial line, and a left jugular central venous line. Next, a 16F catheter was inserted through the right jugular vein for venous return during cardiopulmonary bypass, and a $24 \mathrm{~F}$ catheter was inserted through the right common femoral vein to the inferior vena cava. An $18 \mathrm{~F}$ catheter was inserted in the right common femoral artery to facilitate arterial flow, 